\title{
ABCs for HIV prevention in Kenya: Messages, beliefs, and barriers
}

Julie Pulerwitz

Population Council

Tiffany Lillie

Louis Apicella

Population Council

Ann P. McCauley

Tobey C. Nelson

See next page for additional authors

Follow this and additional works at: https://knowledgecommons.popcouncil.org/departments_sbsr-hiv

Part of the Family, Life Course, and Society Commons, Gender and Sexuality Commons, and the International Public Health Commons

How does access to this work benefit you? Let us know!

\section{Recommended Citation}

Pulerwitz, Julie, Tiffany Lillie, Louis Apicella, Ann P. McCauley, Tobey C. Nelson, Simon Ochieng, Peter Mwarogo, Karusa Kiragu, and Edward Kunyanga. 2006. "ABCs for HIV prevention in Kenya: Messages, beliefs, and barriers," Horizons Research Summary. Washington, DC: Population Council. 


\section{Authors}

Julie Pulerwitz, Tiffany Lillie, Louis Apicella, Ann P. McCauley, Tobey C. Nelson, Simon Ochieng, Peter Mwarogo, Karusa Kiragu, and Edward Kunyanga 


\section{Hgrizons}

\section{ABCs fOR HIV PREVENTION IN Kenya: Messages, Beliefs, and BARRIERS}

A study of how adults and youth perceive and understand the $A B C s$ indicates that while awareness of the terms was generally high, confusion about their meaning was common. Respondents largely supported abstinence and faithfulness but held negative views of condoms. They also highlighted contextual barriers to the adoption of each of the $A B C s$ which programs must address to be effective.

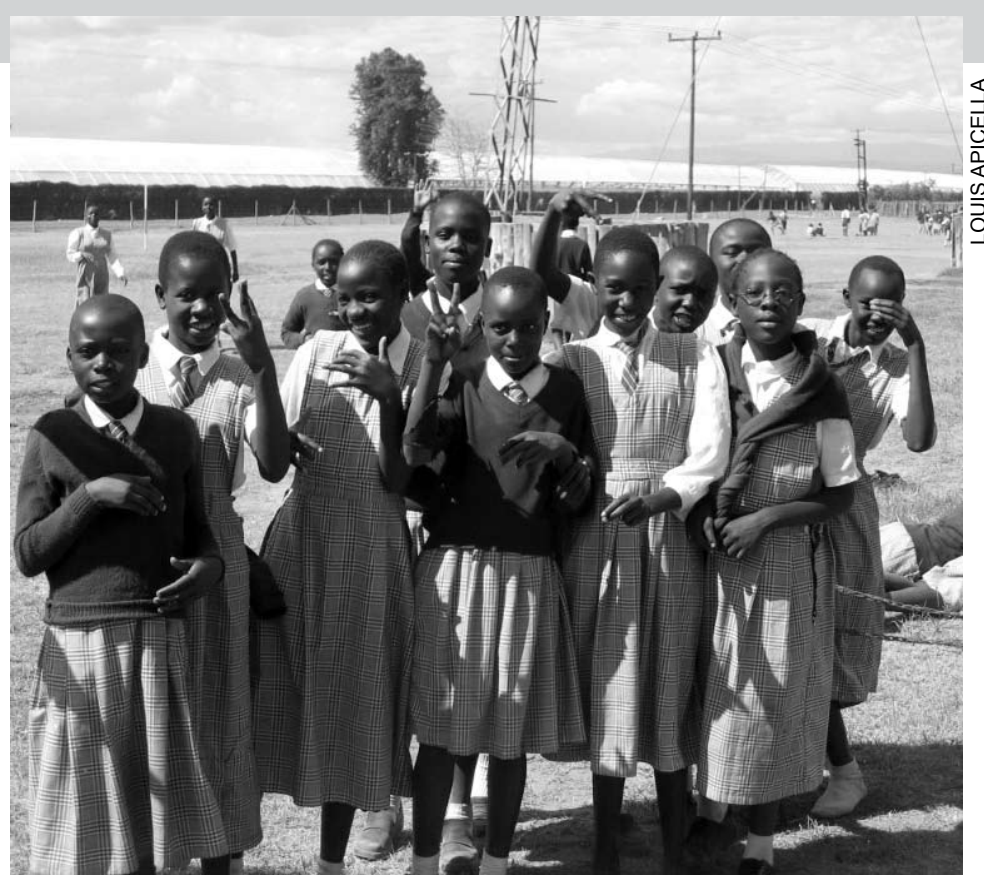

Youth from the study area.

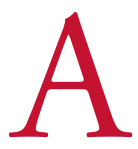
great deal of attention has been focused recently on the promotion of the "ABCs" of HIV prevention-being abstinent or delaying sex, remaining faithful to one sexual partner or reducing the number of sexual partners, and consistently using condoms during sex. Yet even as programs that focus on the ABCs to prevent sexual HIV transmission are rolled out, questions remain about how well different groups in varied cultural contexts actually understand the terms, as well as how best to address challenges to adopting the $\mathrm{ABC}$ behaviors.
The Horizons Program and FHI/IMPACT developed a collaborative research study in 2004 to explore how adults and youth in Kenya define and perceive the $\mathrm{ABC}$ terms and behaviors. Additional objectives of the study were to identify attitudes and norms around the $\mathrm{ABC}$ behaviors that influence perceptions of them, and the role of important actors in transmitting messages about them. Findings highlight potential challenges in promoting each of the $\mathrm{ABC}$ behaviors, as well as some positive elements that can be built upon when developing programs. 


\section{Study Methods}

For findings to be relevant to a wide audience, two groups were selected to represent general youth and adult populations: working adults at flower farms and in-school youth. Surveys were administered to 538 flower farm workers ages 18-49 and 1,365 in-school youth ages 13-19 in two communities in the Nakuru district, Naivasha and Molo. Multiple focus group discussions were also held with both groups.

As part of the surveys, respondents were asked whether they had heard of "abstinence," "being faithful," and "condom use" in the context of HIV prevention. Study participants were also asked to write a definition for each term. Non-definition answers were examined for themes such as value judgments indicative of attitudes toward the behavior (e.g., condom use is ineffective; abstinence is good).

\section{Key Findings}

\section{Most respondents are familiar with the $A B C$}

terms. Both adults and youth had an almost universal awareness of HIV, and the great majority had heard the $\mathrm{ABC}$ terms used in the context of HIV prevention. Specifically, 88 percent of adults and 84 percent of youth had heard of "abstinence," 97 percent of adults and 93 percent of youth had heard of "be faithful," and 95 percent of adults and 84 percent of youth had heard of "condom use."

\section{Abstinence is the most clearly understood term. When asked to define the ABC behaviors in open- ended survey questions, many respondents did not have a clear understanding of the terms. Both groups understood the term "abstinence" the best, and gen- erally described it as not having sex. Compared to adults, youth were more likely to supply a correct answer (46 vs. 39 percent).}

Respondents often misunderstood and confused the term "being faithful" with other concepts and quali- ties, such as loyalty to a friend, or trusting God. When defined in the context of a sexual relationship, it was commonly confused with trusting your partner. Youth were more likely to confuse the term, with only 23 percent answering the question correctly compared to 35 percent of adults.

While the concept of condom use appeared to be relatively well understood, only 17 percent of adults and 13 percent of youth correctly defined "consistent condom use." Many youth, particularly younger students, offered an opinion of condom use rather than a definition. Many adults (43 percent) did not answer the question.

Overall, adults tended to define the ABCs more accurately than youth. Men and women, younger (less than 15 years) and older (15 years or over) youth, and sexually experienced and non-experienced youth tended to have similar clarity about the ABCs.

\section{Negative opinions toward condom use are} widespread. When survey respondents supplied an opinion about the ABCs instead of a definition, they usually cited the advantages and disadvantages of the behaviors. The predominant themes related to condom use, particularly among male and female youth, were that they are ineffective, likely to spread HIV, physically harmful, and immoral. As a group, adults both reported the benefits of condom use (e.g., preventing HIV and other STIs) and held the view that condoms were ineffective.

Respondents expressed many and varied reasons for their negative views toward condom use as well as numerous barriers to their use. For example, adults and youth reported that individuals, including educators, and the media taught them that condoms were ineffective or regularly burst. According to one youth participating in a focus group:

The radio says they have virus. We are told it has small holes that can allow the virus to go through. 
Male and female students shared the opinion that since youth their age should not be having sex, condom use was inappropriate or naughty. Male and female adults reported that condoms were unpopular and difficult to implement because they reduced sexual pleasure, or because raising the issue with partners implied a "lack of trust."

\section{Abstinence and being faithful are viewed positively, but numerous barriers exist. Par-} ticipants had positive attitudes toward abstinence and being faithful. Yet the focus group discussions were frequently tempered with statements on the barriers to the behaviors. Respondents from varied backgrounds - men and women, girls and boysmentioned the driving need for sex and an inability to control sexuality. Both male and female adults expressed their skepticism toward practicing abstinence. According to one flower farm worker:

\section{Abstinence cannot work for both men and women. More for the men. If you are a man you cannot live without doing sex.}

The adults shared similar views about faithfulness to one partner. As one respondent stated:

For women it is possible but for men it is not possible. They say "you cannot eat [the same thing] every day...."...they say that the wife is "Githeri" (beans and maize). So he will say that... his teeth will start aching because of eating Githeri daily.

Respondents also expressed a sense of fatalism - that there is no way to avoid HIV infection so there is no need to engage in risk reduction behaviors such as mutual monogamy. Other respondents believed in potential negative physical repercussions of not having sex, such as body pains or an inability to urinate.

\section{Gender dynamics play a crucial role in the adoption of the ABC behaviors. Gender was} an important theme that was raised by all groups. For example, a number of factors affecting women and girls were raised as barriers to the $\mathrm{ABC}$ behaviors. Female flower farm workers and some female youth highlighted pressure to have sex, often due to economic hardships. Another key factor was genderbased power dynamics inhibiting women's ability to negotiate issues related to sexual behavior. Examples included the decision to have sex or not, gender norms related to men maintaining multiple sexual partners, and the negotiation of condom use. Gender-based violence and rape of girls and women were also commonly cited as insurmountable barriers to the adoption of the ABCs.

Male respondents, including both flower farm workers and in-school youth, often discussed how women prompt and encourage sexual activity through their own behaviors, such as by dressing provocatively. As a male youth expressed, "The way girls dress makes it difficult to abstain.”

\section{Respondents hear mixed messages about the} $A B C s$. Community-driven messages included both that mutual monogamy was a good idea to prevent HIV, and that something was "wrong" if men did not have multiple sexual partners. Both flower farm workers and in-school youth indicated that different institutions sometimes communicated different messages, which they found confusing — such as public health messages promoting one behavior while religious institutions promoted another. Another area of confusion, especially for youth, was how some groups promoted certain behaviors although many people in the groups did not practice those behaviors themselves.

\section{Respondents prefer interpersonal sources of}

information. The radio was reported as a main source of HIV information for both adults and youth. However, when asked about the best way to transmit key $\mathrm{ABC}$ messages, both adults and youth stated a preference for interpersonal and interactive methods, such as workshops. Radio announcements were found to be too general and respondents said they liked the opportunity to discuss issues in detail and to have their questions addressed. Both groups also commonly reported receiving information on the $\mathrm{ABC}$ from friends; however, they were not sure of the reliability of such information. 


\section{Conclusions and Recommendations}

HIV prevention programs that incorporate $A B C$ messages - both in Kenya and elsewhere-should consider a number of lessons from this study. Although most respondents had heard of the ABCs in the context of HIV prevention, much confusion surrounding the actual behaviors existed. This is due in part to respondents receiving conflicting $\mathrm{ABC}$ related messages from different sources. Programs should clearly define the behaviors and coordinate messages so they are consistent and non-conflicting. This recommendation is not new but bears repeating, given the study's findings.

The findings also provide a strong rationale for choosing approaches that extend beyond the simple provision of $\mathrm{ABC}$ messages to more broadly influencing the social norms, policies, and conditions that serve as barriers to the adoption of safer behaviors. These include addressing perceptions of masculinity and norms of male behavior, targeting the social and structural causes of transactional and cross-generational sex, and curtailing gender-based violence.

Abstinence and being faithful to one sexual partner were behaviors supported by study respondents, yet numerous barriers were described, especially for women and girls. HIV prevention activities can build upon the existing support for the behaviors. Complementary activities to address the barriers and enable individuals to enact the behaviors, if they choose to do so, are vital.

Negative beliefs about and discomfort with condoms should be addressed to successfully implement a balanced ABC approach. Debates about the appropriateness and effectiveness of condoms have a long history in the Kenyan context; it is clear that respondents have received inconsistent and negative messages about condoms, especially in-school youth.
Preferred sources of HIV information were interactive and interpersonal, so programs should include related activities. Respondents also indicated that they most often spoke to friends about the ABCs. Peer education programs combined with more traditional sources of health information, such as schools and clinics, could be important strategies in Kenya.

An ongoing intervention in Naivasha being implemented by FHI, builds upon the study findings by bringing together various NGO, civil, and faithbased organizations to coordinate a prevention strategy that is balanced and does not include contradicting messages. The intervention includes interactive and interpersonal activities to address sensitive sexual norms and barriers to risk behaviors, and billboards and IEC materials to reinforce $\mathrm{ABC}$ messages on a more massive scale. In addition, attempts are being made to integrate complementary interventions, such as gender-based violence reduction programs.

June 2006

\section{Acknowledgments}

Principal study investigators included Julie Pulerwitz and Karusa Kiragu, PATH/Horizons; Tiffany Lillie and Edward Kunyanga, formerly of FHI; Louis Apicella, Horizons/Population Council; Ann McCauley, formerly of Horizons; Tobey Nelson, Horizons/ICRW; and Peter Mwarogo and Simon Ochieng, FHI.

The authors would like to thank Helen Odindo, consultant, for her help with data collection. Thanks also to the reviewers of the report, including Michael Cassell, USAID; Naomi Rutenberg, Population Council; Colleen Conroy, formerly of PATH; and Paul Nary and John McWilliams, FHI. A special acknowledgment to Carol Larivee, formerly of FHI, who was a major impetus behind this study.

Suggested citation: Pulerwitz, Julie, Tiffany Lillie, Louis Apicella, Ann McCauley, Tobey Nelson, Simon Ochieng, Peter Mwarogo, Karusa Kiragu, and Edward Kunyanga. 2006. "ABCs for HIV prevention in Kenya: Messages, beliefs, and barriers," Horizons Research Summary. Washington, DC: Population Council.

\section{Hprizons N}

Population Council/Horizons

Communications Unit

4301 Connecticut Avenue, NW

Suite 280

Washington, DC 20008
(1) Population Council

Tel: $202-237-9400$

Fax: 202-237-8410

horizons@pcdc.org

www.popcouncil.org/horizons
This publication was made possible through support provided by the President's Emergency Plan for AIDS Relief through the Office of HIV/ AIDS, Bureau of Global Health, U.S. Agency for International Development (USAID), under the terms of Award No. HRN-A-00-97-00012-00. The opinions expressed herein are those of the authors and do not necessarily reflect the views of USAID. 